\title{
Concentration of NO, C-Reactive Protein, Magnesium, Calcium, and Phosphorous in Patients with Arthritis Gulzar Ismael Ibrahim $(\mathrm{PhD})^{1}$, Saman Muhsin Abdulkareem(MSc) ${ }^{2}$, Lutfia Muhammed Hasan(MSc) ${ }^{3}$
}

\begin{abstract}
Background: Rheumatoid arthritis (RA) is an autoimmune disorder, occurs when there are attacks of the immune system on body's tissues especially the joint, causing a painful, swelling, that finally results in bone deformity, increased free radical level in defect joint and reduce the level of the antioxidant system can cause tissue damage. Serum $C$-reactive protein (CRP) can be estimated as an index of the pathogen in RA.A chronic inflammatory case as in RA is probable to change magnesium, calcium and phosphorus level in the serum.

Objective: To study the impact of elevated level of NO in serum of RA as a free radical involved in pathogens of arthritis and the role of CRP as an indicator for inflammation. With changes in the level of serum magnesium, calcium, and phosphors in patient with RA.

Patients and Methods: Forty patient with RA were studied and then compared with the same number of healthy subjects. Nitrite was estimated by Griess reaction using VCL3 as a reducing agent by spectrophotometer at 540nm. CRP was detected by using Avitex-CRP kit and serum levels of $\mathrm{Ca}, \mathrm{Mg}$, and $\mathrm{P}$ was measured by fully automated random-access biochemistry analyzer (Cobas Integra 400 plus).

Results: In our study, it was found that the mean NO levels were 77.33 \pm 6.37 in RA and $26.678 \pm 3.637$ in healthy subjects, significant at $\mathrm{p}<0.0001$. CRP test was found to be positive in 34/40 cases of RA and none of the controls. The $\mathrm{Mg}$ and $\mathrm{Ca}$ level were less than normal and significances higher change in $\mathrm{P}$ level.

Conclusion: Our result finding that there is a close relation between oxidative stress and RA, in addition to CRP as a marker for inflammation, $\mathrm{Mg}, \mathrm{Ca}$ and $\mathrm{P}$ level can be studied for the preferabletherapeutic management of RA.

Key words: Nitric oxide, CRP, Ca, Mg, P, Rheumatoid Arthritis (RA).

Corresponding Author: gulzar.ibrahim@su.edu.krd

Received: $24^{\text {th }}$ June 2018

Accepted: $7^{\text {th }}$ October 2018

https://doi.org/10.26505/DJM

${ }^{1,3}$ Department of Chemistry- College of Education- Salahaddin University-Erbil- Iraq.

${ }^{2}$ Department of Biology-College of Education- Salahaddin University-Erbil-Iraq.
\end{abstract}

\section{Introduction}

Rheumatoid arthritis is an autoimmune disease that influences the Synovial joint which is characterized by erosive synovitis, that leads to damaging the cartilage and bones as well as systemic complications, including cardiovascular, pulmonary, psychological, and various skeletal problems
[1]. RA significantly lowers patient's functional capacity, raises the morbidity and mortality rates, and results in significant costs to the health and social care systems [2]. The prevalence of RA in the worldwide population is about $1 \%$ and female are a lot of affected than male [3].Although 
individuals of any age can be affected but the onset is more recurrent in 40's or 50's. The exact reason of RA remains unknown [4]. At this time some of the theories of pathogenesis of RA include the autoimmune reactions, mediators of tissue injury, genetic susceptibility, and or triggering antigens [5].

Nitric oxide (NO) is a small molecule produced endogenously that has serious functions in cellular signaling and take part in diverse physiological processes. Opposite biological effectscan be expected from (NO), depending upon various environmental and pathophysiological situations[6].

Autoimmune phenomena and damage of connective tissue within the synovial joint can be resulted from oxidative stress formed within inflamed joint. Radical species that possess oxidative activity, which include reactive nitrogen species (RNS) and reactive oxygen species (ROS), mediate and cause cartilage damage[7]. At the location of synovial inflammation, NO mediates various cell functions, including signal transduction, mitochondrial function, and apoptosis [8]. NO has arisen as significant mediator inRA synovium. It has been demonstrated that patients with RA, ankylosing spondylitis, and osteoarthritis have high levels of NO synovial fluid and blood serum [9].

Hepatocytes synthesize an acute phase protein called CRP to counter proinflammatory cytokines in particular IL-6. It has been consideredvery importantin RA as an inflammatory marker and it is been proposed to mediate part of the complement activation in RA[10].
Magnesium (Mg) is one of the most significant micronutrients for human health and is highly associated with immune responses[11]. $\mathrm{Mg}$ levels are altered in chronic inflammations and low level of $\mathrm{Mg}$ have been suggested to be marker of RA[12]. In human studies, individuals with decreased intake of $\mathrm{Mg}$ were linked to elevated CRP levels[13].

The calcium role is not clear in RA, however, the relationship between calcium, vitamin $\mathrm{D}$, and parathyroid hormone suggests the possible role of calcium in RA and there is a change in mineral within bone which are calcium, and phosphorus [14]. Changes in lipid profile have been observed in different inflammatory disease such as RA [15]. RA patients are in increased risks of atherosclerosis and cardiovascular diseases (CVD) than the overall population [16].

This study was aimed to study NO level as a marker of oxidative stress in patients with RA and to correlate it and the possible changes in CRP in serum, as well as the changes in $\mathrm{Mg}, \mathrm{Ca}$, and $\mathrm{P}$ level in recently diagnosed RA patients compared to healthy subjects.

\section{Patients and Methods}

\section{Subjectsand Samples}

The data in this article has been collected from Rizgari Hospital. The sample was taken from a group of 40 patients with RA (15 male and 25 female), age (45-70 years). The control was diagnosed if they having any diseases such as diabetes, infectious diseases. RA was diagnosis based on clinical histories such as ESR and rheumatoid factor. The 
patient who fulfill with American Rheumatism Association (ARA).

To estimate NO, CRP, calcium, magnesium, and phosphorus, $10 \mathrm{ml}$ was drawn from forearm vein for both controls and patients. The collected blood samples were allowed time to form a clot at room temperature and then centrifuged for 10 minutes at 3000rpm. The separated serums were drawn and divided into three parts. Finally, the separated serums were kept in a deep-freezing atmosphere $\left(-18^{\circ} \mathrm{C}\right)$ until they are utilized.

\section{Instruments}

Different instruments have been used for this study including spectrophotometer (LKB, Model 4050), centrifuge Centra 4, International (IEC), Cobas Integra 400 Plus and analytical balance.

\section{Chemicals}

All the common laboratory chemicals and reagents used in this study were of analargradeunles,purchase from (Merk), Analar ethanol, Griess reagent, vanadium (111) chloride, sodium nitrite,Avitex-CRP kit, 5-nitro-5-methyl-BAPTA (NM-BAPTA), EDTA, Chlorophosphonazo-III, ammonium molybate, sulphuric acid, EGTA(ethyleneglycol-tetraacetic-acid), and sodiumhydroxide.

\section{Measurement of Serum NO}

Serum NO evaluated by Griess reaction, Griess reaction is based on the principle that, in an oxygenated solution, NO decomposes to form nitrite (NO2-) and nitrate (NO3-). The only steady product formed by spontaneous auto-oxidation of $\mathrm{NO}$ in oxygenated solutions is nitrite (NO2-). Nitrite reacts with sulfanilamide and heterocyclic amine of naphthylene-ethylene-diamine (Griess reagent) under conditions of low $\mathrm{pH}$ to form a magenta colored azo dye that can be measured by the spectrophotometer at 540 nm [17]. Ethanol was cooled at an average of $1: 2 \mathrm{v} / \mathrm{v}\left(0{ }^{\circ} \mathrm{C}\right)$ and was added to the serum samples, which were then vortexed and deproteinized. The collected samples were centrifuged for 5 minutes at 14000rpm, following a 30-minute incubation at $0{ }^{\circ} \mathrm{C}$.

The supernatant was used for the measurement of NO. Vanadium (III) $\mathrm{Cl}$ (reducing agent) was injected into the supernatant and the measurement of NO, produced as a result of the reduction of nitrate, to nitrite, Griess reagent was added into the mixture. Then they mixed well by vortexing for about 2 minutes. This sodium nitrite reacts with Griess reagent [18].

Finally, the absorbance of the product spectrometrically reads by using a $540 \mathrm{~nm}$ filter. The nitric oxide concentration in serum sample was determined from standard curve established by 0 to $120 \mu \mathrm{mol} / \mathrm{L}$ of sodium nitrite by taking OD of the serum sample [19].

\section{Detection of CRP}

To detect CRP in the serum of the patient with RA and control, agglutination test was done by using Avitex-CRP kit. Avitex-CRP latex partials are coated with human antibodies. clear agglutination will be visible on the slide when the Avitex-CRP is mixed with serum and when there is a high level of CRP. The test is measured as negative when 
the CRP concentration in serum is less than 6 $\mathrm{mg} / \mathrm{liter}$ and positive when the CRP serum concentration is more than $6 \mathrm{mg} /$ Liter [20].

\section{Estimation of Calcium}

Calcium ions react with 5-nitro-5-methylBAPTA (NM-BAPTA) under alkaline conditions to produce a complex. This complex reacts in the later step with EDTA. The alteration in absorbance is directly proportional to the calcium level and is measured photometrically. The Cobas Integra 400 Plus system automatically calculates the analyte concentration of every sample [21].

\section{Estimation of Phosphorus}

Ammonium molybate combines with phosphate in present of sulphuric acid to produce a phosphomolybate complex. The absorbency increase is directly proportionate to the phosphate concentration. The Cobas Integra 400 Plus system automatically calculates the analyte concentration of each sample [22].

\section{Estimation of Magnesium}

Chlorophosphonazo-III (CPZIII) binds to magnesium and causes an absorbance raise at $659 \mathrm{~nm}$. Egtazic acid (EGTA) is used to inhibit bindings of calcium to CPZIII. $\mathrm{Mg}++$ + CPZIII pH $7.5>$ Mg-CPZIII complex. Nonspecific absorbance interferences are decreased by the addition of EDTA (ethylenediaminetetraacetic acid), which removes magnesium from the magnesiumCPZIII complex and permit for a precise sample blank measurement.

$\mathrm{Mg}+\mathrm{CPZIII}$ complex + EDTA at $\mathrm{pH} 7.5 \rightarrow$ Mg-EDTA + CPZIII.
The variation in absorbance between the magnesium-CPZIII complex and the EDTA treated complex is the absorbance due to magnesium only. The analyte concentration of each sample automatically calculates by the Cobas Integra 400-plus system [23].

\section{Statistical analysis}

Statistical analysis was done by using student t-test to compare between the two groups which performed by GraphPad Prism 6 (GraphPad Software) with the level of significance set at $\mathrm{p}<0.05$. The data of this study were given as mean \pm standard deviation.

\section{Results}

Forty patients ( 15 male and 25 female) were diagnosed with rheumatoid arthritis at Rizgari hospital with 40 healthy people who represent controls.

\section{Age and Sex}

In this study patient with RA belonged to the age group of 45-70 years. Among patients of RA 15 patients were males and 25 were females as shown in table 1 . The mean $\pm S D$ of age in males was $53.35 \pm 8.14$ and the mean $\pm \mathrm{SD}$ of the female was $55 \pm 11.3$.

\section{Serum level of NO}

Serum level of NO $(\mu \mathrm{mole} / \mathrm{L})$ of arthritis patient and control are shown in figure 1 . The mean value of serum NO in RA subjects was found to be $77.733 \pm 6.370$ and that of the controls was $26.678 \pm 3.637$. The variance in the mean value was statistically significant at $\mathrm{p}<0.0001$.

\section{Serum CRP Levels}

Detection of CRP in the subjects with and without RA are given in table 2 , in the 
present study 34 of 40 samples of RA were detected to be positive to CRP test while the whole of the subjects without RA was negative for the same test.

Table (3)and Figure 2 shows $\mathrm{Mg}, \mathrm{Ca}$ and Phosphorus levels in $(\mathrm{mg} / \mathrm{dl})$ of patients with RA and control. Serum levels of magnesium and calcium were decreased $(1.2598 \pm 0.3829$ and $7.088 \pm 0.306$, respectively) compared with control $(2.5075 \pm 0.6776$ and $8.410 \pm 0.338$, respectively) while phosphorous levels were significantly increased in RA group $(4.230 \pm 0.430)$ in comparison to control group $(2.575 \pm 0.437)$.

Table (1): Gender and age of rheumatoid patients (Mean $\pm \mathrm{SD}$ ).

\begin{tabular}{|l|c|}
\hline \multicolumn{2}{|c|}{ CasesNo. $=40$} \\
\hline \hline Sex (male/female) & $15 / 25$ \\
\hline \hline Age (years) & $53.35 \pm 8.14$ \\
\hline \hline Male & $55 \pm 11.3$ \\
\hline \hline Female & \\
\hline
\end{tabular}

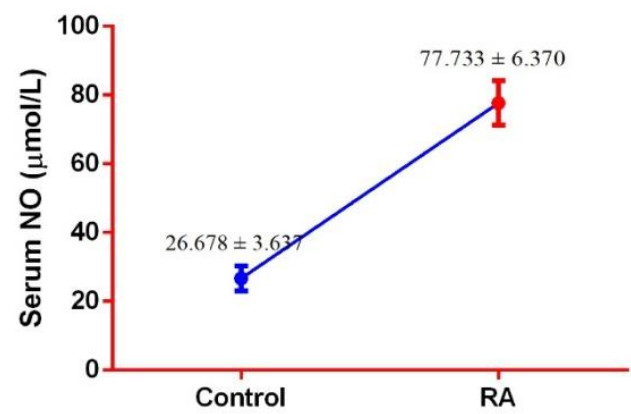

Figure (1): Levels of serum NO in patients with RA and Controls (Mean $\pm \mathrm{SD}$ ).

Table (2):Detection of CRP in serum from subjects with and without RA.

\begin{tabular}{|l|c|c|}
\hline \multicolumn{1}{|c|}{ Groups for CRP } & No. of cases & No. of positive cases \\
\hline \hline RA patients & 40 & 34 \\
\hline \hline Controls & 40 & NIL \\
\hline
\end{tabular}

Table (3): Serum level of $\mathrm{Mg}, \mathrm{Ca}$ and Phosphorus(Mean $\pm \mathrm{SD}$ ).

\begin{tabular}{|l||c||c||c||}
\hline \multicolumn{1}{|c|}{ Parameters } & Subjects with RA & Subjects without RA & p-value \\
\hline \hline Magnesium $(\mathrm{mg} / \mathrm{dl})$ & $1.2598 \pm 0.3829$ & $2.5075 \pm 0.6776$ & $<0.0001^{*}$ \\
\hline Calcium $(\mathrm{mg} / \mathrm{dl})$ & $7.088 \pm 0.306$ & $8.410 \pm 0.338$ & $<0.0001^{*}$ \\
\hline \hline Phosphorus $(\mathrm{mg} / \mathrm{dl})$ & $4.230 \pm 0.430$ & $2.575 \pm 0.437$ & $<0.0001^{*}$ \\
\hline
\end{tabular}




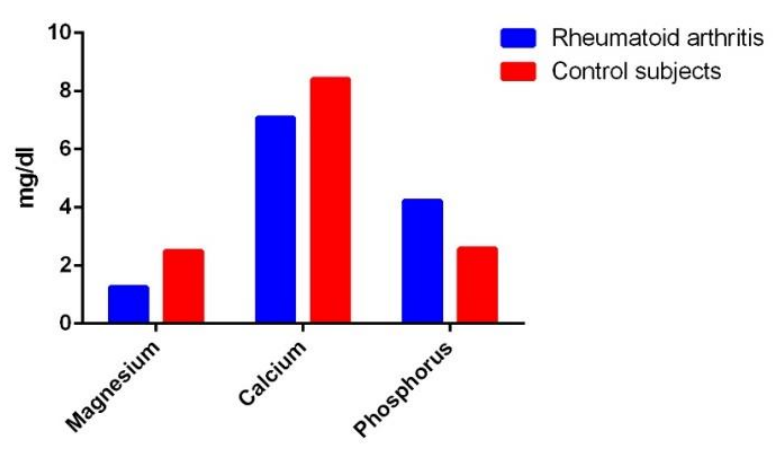

Figure (2): Serum levels of some minerals in subjects with and without RA.

\section{Discussion}

Nitric oxide is a singling molecule in numerous physiological and pathological processes. NO has a role in blood vessels dilation, raising blood supply and dropping blood pressure, its known as an endotheliumderived relaxing agent [24]. NO synthesized via several nitric oxide building enzymes from L-arginine, O2, and NADPH. NO has a very short life as a free radical and consider as a potent inflammatory mediator, its interact with the $\mathrm{O} 2$ compound containing iron [25].

Our study shows that serum NO level is highly significant $(\mathrm{P}<0.0001)$ in $\mathrm{RA}$ patient compared with healthy control. That may be due to two possible reasons. 1- Increasing in synovial inflammation, which causes increases in NO level, synovial fluid eventually enters blood circulation .2- other possible cause may be due to the generation of NO by vascular system and other cells [9]. When NO transforms to peroxynitrate radical (ONOO') it may cause cell damage or convert to another product like $\mathrm{OH}(\mathrm{NO} 2+$ hydroxyl radical). production of $\mathrm{NO}$ in inflammation joint may participate to immigrate to the synovial and periarticular tissue resulting in the destruction of cartilage and bone within the joint by inflammatory cells [26].

In this study, the concentration of CRP was higher in the cases compared to healthy subjects. Similarly, [27] and [28] observed the high value of CRP indicated the presence of inflammation. CRP has an annular ring shape pentameric protein, its production in the liver in response to inflammation and can play a role in the pathogenesis of RA. Cytokines which is considered as a proinflammatory can be released in response to interleukin-1-beta and tumor necrosis factor- $\alpha$, that stimulated the liver to increase inflammatory process, on another hand interleukin-6 stimulate the liver to secrete CRP. Many studied consider that CRP may directly contribute to the inflammatory by stimulating many types of cytokines like IL13 and IL-6 [29].

Lower calcium level may be due to insufficient calcium intake and quicken 
osteoporosis, more sodium intake in our food may cause calcium depletion [30].

Free radical that produced by ROS that case chronic inflammatory cells nearby bone with subsequent bone destruction [31]. Many drugs shave an affected-on calcium metabolism and cause a low level of calcium in RA. It was assuming that high level of phosphorous was related to tissue hypoxia with an elevated in ATP breakdown resulting in the release of inorganic phosphorous from cells. However, hypoxia create by hypertrophy and hyperplasia within synovial joints [32].

Acidosis will promote shift of phosphorous from intracellular to extracellular pool.

Serum magnesium level decreases significantly in RA patient compared with control possibly due to chronic inflammatory conditional and autoimmune injury [33].

\section{Conclusion}

Diagnosis and determine its diseases activity of RA can be assessed by determining some biochemical marker in blood, such as NO level which plays an important role in the pathogenesis of RA. The further study requires to determine the exact role of NO in the assessment of disease activity in RA cases.

CRP has shown a big role as a biomarker in determining the intensity of inflammation and better control of the condition. It was observed that Magnesium, Calcium in RA a low level in serum whereas Phosphorous has shown a high level in contrast to control, that can be concluded to be a danger factor for RA cases. Our suggestion that change at a mineral level has an interesting role in patients with RA, which participate in the pathological process.

These results recommend to increase $\mathrm{Mg}$, $\mathrm{Ca}, \mathrm{P}$ in the dies with a supplement that might be helpful for a patient with RA. Further studying is necessary to estimate various biochemical markers that influences patient with RA.

\section{References}

[1] McInnes IB, Schett G. The pathogenesis of rheumatoid arthritis. New England Journal of Medicine. 2011;365(23):2205-19.

[2]Lajas C, Abasolo L, Bellajdel B, Hernández-García C, Carmona L, Vargas E, et al. Costs and predictors of costs in rheumatoid arthritis: a prevalence-based study. Arthritis Care \& Research. 2003;49(1):64-70.

[3]Gibofsky A. Epidemiology, pathophysiology, and diagnosis of rheumatoid arthritis: A Synopsis. The American journal of managed care. 2014;20(7 Suppl):S128-35.

[4] Krune S, Simon L. Rheumatoid arthritis: clinical features and pathogenic mechanism. The Medical Clinics of North America. 1986;30:263-83.

[5]Kumar V, Abbas AK, Fausto N, Aster JC. Robbins and Cotran pathologic basis of disease, professional edition e-book: elsevier health sciences; 2014.

[6]Li H, Wan A. Apoptosis of rheumatoid arthritis fibroblast-like synoviocytes: possible roles of nitric oxide and the thioredoxin 1. Mediators of inflammation. $2013 ; 2013$. 
[7] Vasanthi P, Nalini G, Rajasekhar G. Status of oxidative stress in rheumatoid arthritis. International journal of rheumatic diseases. 2009;12(1):29-33.

[8] Phillips DC, Dias HI, Kitas GD, Griffiths HR. Aberrant reactive oxygen and nitrogen species generation in rheumatoid arthritis (RA): causes and consequences for immune function, cell survival, and therapeutic intervention. Antioxidants \& redox signaling. 2010;12(6):743-85.

[9] Ersoy Y, Özerol E, Baysal Ö, Temel I, MacWalter R, Meral Ü, et al. Serum nitrate and nitrite levels in patients with rheumatoid arthritis, ankylosing spondylitis, and osteoarthritis. Annals of the rheumatic diseases. 2002;61(1):76-8.

[10] Molenaar ET, Voskuyl AE, Familian A, van Mierlo GJ, Dijkmans BA, Hack CE. Complement activation in patients with rheumatoid arthritis mediated in part by Creactive protein. Arthritis \& Rheumatology. 2001;44(5):997-1002.

[11] Tam M, Gomez S, Gonzalez-Gross M, Marcos A. Possible roles of magnesium on the immune system. European journal of clinical nutrition. 2003;57(10):1193.

[12] Lucia $M$, Isabela $S$, Minerva $G$. Changes of serum magnesium level in patients with rheumatoid arthritis stage I-II, before treatment. Med Con. 2011;6(2):9-16. [13] King DE, Mainous III AG, Geesey ME, Woolson RF. Dietary magnesium and Creactive protein levels. Journal of the American College of Nutrition. 2005;24(3):166-71.
[14] Makhdoom A, Rahopoto M, Laghari M, Qureshi Pir A, Siddiqui K. Bone mineral levels in rheumatoid arthritis. Medical Channel. 2009;15(3):99-102.

[15] Steiner G, Urowitz MB, editors. Lipid profiles in patients with rheumatoid arthritis: mechanisms and the impact of treatment. Seminars in arthritis and rheumatism; 2009: Elsevier.

[16]Kaplan MJ. Cardiovascular complications of rheumatoid arthritis: assessment, prevention, and treatment. Rheumatic Disease Clinics. 2010;36(2):40526.

[17] Miranda KM, Espey MG, Wink DA. A rapid, simple spectrophotometric method for simultaneous detection of nitrate and nitrite. Nitric oxide. 2001;5(1):62-71.

[18] Moshage H, Kok B, Huizenga JR, Jansen P. Nitrite and nitrate determinations in plasma: a critical evaluation. Clinical chemistry. 1995;41(6):892-6.

[19] Ghasemi A, Hedayati M, Biabani H. Protein precipitation methods evaluated for determination of serum nitric oxide end products by the Griess assay. JMSR. 2007;2(15):29-32.

[20] Al-khafaji ZAE. Determination The Levels Of C-Reactive Protein In Rheumatoid Arthritis Patients In Babylon Province/Iraq. AL-QADISIYAH MEDICAL JOURNAL. 2017;5(8):17-22.

[21] Bourguignon C, Dupuy AM, Coste T, Michel F, Cristol JP. Evaluation of NMBAPTA method for plasma total calcium measurement on Cobas 8000®. Clinical biochemistry. 2014;47(7-8):636-9. 
[22] Muñoz MA, Balón M, Fernandez C. Direct determination of inorganic phosphorus in serum with a single reagent. Clinical chemistry. 1983;29(2):372-4.

[23] Ferguson JW, Richard J, O'laughlin J, Banks C. Simultaneous Spectrophotometric Determination of Calcium and Magnesium with Chlorophosphonazo III. Analytical Chemistry. 1964;36(4):796-9.

[24] Farrell AJ, Blake DR, Palmer R, Moncada S. Increased concentrations of nitrite in synovial fluid and serum samples suggest increased nitric oxide synthesis in rheumatic diseases. Annals of the rheumatic diseases. 1992;51(11):1219.

[25] Weinberg JB, Lang T, Wilkinson WE, Pisetsky DS, St Clair EW. Serum, urinary, and salivary nitric oxide in rheumatoid arthritis: complexities of interpreting nitric oxide measures. Arthritis research \& therapy. 2006;8(5):R140.

[26] Kaur H, Halliwell B. Evidence for nitric oxide-mediated oxidative damage in chronic inflammation nitrotyrosine in serum and synovial fluid from rheumatoid patients. FEBS letters. 1994;350(1):9-12.

[27] Milovanovic M, Nilsson E, Järemo $P$. Relationships between platelets and inflammatory markers in rheumatoid arthritis. Clinica chimica acta. 2004;343(12):237-40.

[28] limiuk P, Sierakowski S, Chwiećko J. Serum interleukin 6 (il-6A) concentration correlates with matrix metalloproteinases and their tissue inhibitors in rheumatoid arthritis. Polskie Archiwum Medycyny Wewnetrznej. 2003;109(2):119-23.
[29] Ballou SP, Lozanski G. Induction of inflammatory cytokine release from cultured human monocytes by C-reactive protein. Cytokine. 1992;4(5):361-8.

[30] Stone J, Doube A, Dudson D, Wallace $\mathrm{J}$, editors. Inadequate calcium, folic acid, vitamin $\mathrm{E}$, zinc, and selenium intake in rheumatoid arthritis patients: results of a dietary survey. Seminars in arthritis and rheumatism; 1997: Elsevier.

[31] Garrett IR, Boyce BF, Oreffo R, Bonewald L, Poser J, Mundy GR. Oxygenderived free radicals stimulate osteoclastic bone resorption in rodent bone in vitro and in vivo. The Journal of clinical investigation. 1990;85(3):632-9.

[32] Walwadkar S, Suryakar A, Katkam R, Kumbar K, Ankush R. Oxidative stress and calcium-phosphorus levels in rheumatoid arthritis. Indian Journal of Clinical Biochemistry. 2006;21(2):134.

[33] Chavan VU, Ramavataram D, Patel PA, Rupani MP. Evaluation of serum magnesium, lipid profile and various biochemical parameters as risk factors of cardiovascular diseases in patients with rheumatoid arthritis. Journal of clinical and diagnostic research: JCDR. 2015;9(4):BC01. 